\title{
Natural Ventilation by Air Captors and Extractors Sheds in Hospitals in Brazil: Wind Tunnel Measurements
}

\author{
Marieli Azoia Lukiantchuki ${ }^{1}$, Rosana Caram ${ }^{1}$, Edson Matsumoto ${ }^{2}$ and Lucila Chebel Labaki ${ }^{2}$ \\ 1. Architecture and Urban Planning Institute of São Carlos, University of São Paul, São Paulo 13566-590, Brazil \\ 2. Department of Architecture and Construction, University of Campinas, São Paulo 13083-889, Brazil
}

\begin{abstract}
Natural ventilation is an efficient design strategy for the passive cooling of buildings, especially in tropical countries such as Brazil. Among the ventilation strategies, sheds can be highlighted. These structures consist of roof openings that work as air captors or extractors depending on their location in relation to the prevailing wind directions. The hospitals of the Sarah Network, designed by the Brazilian architect João Filgueiras Lima, Lelé, are worldwide known for using these elements to improve natural ventilation. This paper analyses the natural ventilation performance of sheds for air collecting and extracting in two Sarah hospitals located in the cities of Salvador and Rio de Janeiro. In each building, the sheds were analyzed for air extracting and collecting. The analyses were carried out by reduced physical models in an atmospheric boundary layer wind tunnel. The wind velocity was measured at external and internal points of the buildings, using hot-wire anemometers. The results show that the wards in Rio de Janeiro hospital are 17\% more ventilated than the ones in the Salvador hospital. However, this difference occurs not only because of the collecting sheds but also because of set of openings and the configuration of the covering in hospitals in Rio de Janeiro.
\end{abstract}

Key words: Natural ventilation, air captors and extractors sheds, wind tunnel, João Filgueiras Lima.

\section{Introduction}

Natural ventilation is one of the most important strategies for the passive cooling of buildings, providing thermal comfort and helping to improve the health of their users due to internal continuous air renewal. Furthermore, this strategy reduces the energy consumption, avoiding the use of mechanical ventilation and air conditioning systems. Typically, the energy cost of a naturally ventilated building is $40 \%$ lower than that of an air-conditioned building [1].

Brazil is a tropical country and most of its territory has warm and humid climate. Thus, the use of natural ventilation can be an efficient strategy to achieve thermal comfort without using mechanical cooling [2]. The use of this strategy is not so efficient in regions where external winds are not frequent. This occurs in

Corresponding author: Marieli Azoia Lukiantchuki, Dr., research fields: natural ventilation, environment confort, thermal confort and architecture design. E-mail: mlukiantchuki@yahoo.com.br. cities characterized by weak winds, periods without winds or lack of adequate spaces for the circulation of air inside the urban net. This problem can be minimized by using strategies of natural ventilation on the covering of buildings in two ways: (1) ventilation by the stack effect, in which air pressure differences are originated by differences in temperature between the internal and external air to the building; (2) use of wind captors with openings above the covering level.

Among these solutions, solar chimneys, wind towers and sheds can be cited. Solar chimneys use the sun energy to increase pressure differences between different points and, consequently, improve the flow of natural ventilation [3]. Researches conducted in several countries have shown the effectiveness of using this strategy to increase the natural ventilation in internal spaces [4-7]. Furthermore, a research carried out by Neves et al. [8] highlights that the use of solar chimneys in tropical countries, such as Brazil, is highly efficient.

Likewise, wind towers of different shapes have 
been tested by several researchers to find the best ventilation performance $[9,10]$. In these towers, the winds are captured in an altitude with fewer obstructions, allowing winds with higher velocity, lower temperature and less dust. These devices can be coupled to water tanks of houses to work as air collectors or extractors. The results have shown that the use of wind towers in water tanks increased the internal air velocity by $100 \%$ in some rooms. In addition, improvements in the air distribution have been observed, reducing the areas of stagnation [11].

Finally, sheds can be designed for both air capturing and extracting, depending on the orientation of the openings in relation to the prevailing wind directions. The most common examples of sheds are known as "sawtooth", whose shape is rectangular and without many variations. However, the work of Brazilian architect João Filgueiras Lima, known as Lelé, whose sheds with aerodynamic shapes are present in most of his projects (Fig. 1), was highlighted.

One of the first researches related to the sheds was developed by Gandemer et al. [12]. This researcher evaluated the effects of different locations of sawtooth roofs with respect to the central axis of the construction. Air captors and extractors sawtooths were evaluated. The captor sawtooth is more efficient when located in the first half of the roof, whereas the extractor sawtooth is more efficient when located in the second half of the roof. There was a 50\% internal air velocity increase when the device worked as extractor and $30 \%$ when it worked as a captor. Furthermore, the authors also determined that the area of the shed should be larger than $20 \%$ of the cross-sectional area of the building and perpendicular to the wind direction. The average internal air velocity in buildings with cross ventilation can increase approximately $40 \%$ when the shed works as air extractor and $15 \%$ when it works as an air captor.

Some researches about $\mathrm{Cp}$ (pressure coefficients) in sawtooth roofs have been developed by Stathopoulos and Saathoff $[13,14]$. In these studies, the dependence of $\mathrm{Cps}$ in relation to the number of sheds on the roof was investigated. Models with one, two and four sheds with $15^{\circ}$ of inclination were tested in wind tunnel. The results show that in most areas of coverage, the values obtained for models with two and four sheds are similar to data obtained in the model with one shed. However, the measures near the edge of the roof of the models with two and four sheds are $50 \%$ larger than the data in the model with one shed.

Holmes [15] analysed the pressure on buildings with sawtooth roof with $20^{\circ}$ of inclination. The results were incorporated in the Australian Standard AS1170.2 (1989), which is the only standard that provides the pressure coefficients for buildings with sawtooth roof. Blackmore [16] investigated the influence of the width of the building on the pressure distribution on roofs with two sawteeth.

Through this literature review, it is noted that the sheds have been little explored by architects and few researches about the performance of this strategy have been developed, mainly about the performance of air captors and extractors sheds with aerodynamic shapes. However, despite this situation, the work of the Lelé should be highlighted. The air extractor and captor sheds with aerodynamic shapes are present in most of his projects, mainly the Sarah Network of Hospitals. Lelé has been designing sheds for almost 50 years. Based on his experiences and local climatic factors, in some cases, he prioritizes the extraction of air through stack effect and, in other cases, he prioritizes the capture of natural winds [17-19].

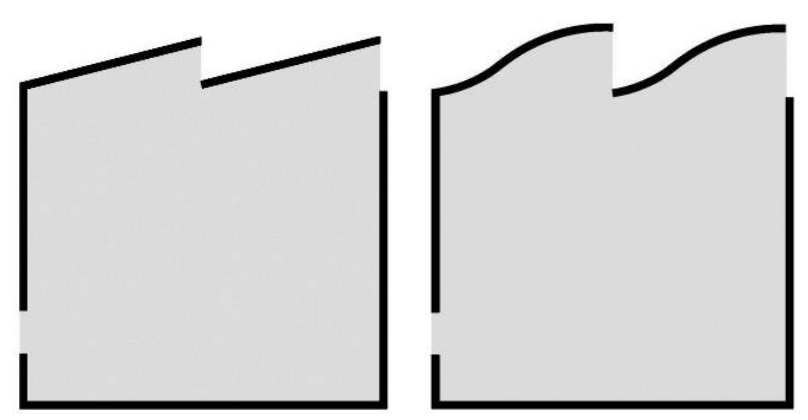

Fig. 1 Sawtooth roof and aerodynamic sheds, respectively. 
The Sarah Network of Hospitals are constituted by 10 hospitals, located in several cities, whose climate is mostly warm and humid. In an attempt to improve the efficiency of the sheds regarding natural ventilation, their geometry in each new building has been modified. The changes in these architectural elements are of great importance because, according to Hooff et al. [20], one of the main parameters that affect natural ventilation is the geometry of the building.

Perén et al. [21] also evaluated threes models of sheds designed by Lelé (two hospitals of Sarah Network and electoral tribunal building of Brazil) through computational simulation. In this research, the authors discussed the influence of changes in the formats of these devices for natural ventilation. The results showed a better performance of the model of the electoral tribunal, due to smoother surface, showing no interruptions or obstacles in the airflow, and, consequently, the air velocity is higher.

In this research, two Sarah hospitals, located in the cities of Salvador and Rio de Janeiro, both with warm and humid climate, were chosen for analyses due to their difference in geometry and orientation of sheds. The headroom of the Salvador hospital is $3.00 \mathrm{~m}$ high in the lower part of the sheds and $4.50 \mathrm{~m}$ high in the upper part. The sheds are limited by rooms and the air is captured by underground floor and then, the warm air is extracted by the sheds (stack effect) through the positioning of their openings leeward (Fig. 2).

Unlike this building, in the Rio de Janeiro hospital, the sheds are totally independent of the internal spaces with ceiling height variable and higher than $8.00 \mathrm{~m}$. The internal rooms have translucent polycarbonate liners that allow the passage of air and natural light. In this case, the sheds are oriented windward, prioritizing the wind entry through the cover. However, there are also openings on the leeward side, which allow permanent natural ventilation through the cover and work as a thermal protection to the building (Fig. 3).
It is important to highlight that, as the Sarah Network is constituted by rehabilitation hospitals designed for the treatment of patients with locomotor system diseases, the use of natural ventilation is extremely favorable. The absence of patients with infectious diseases causes no impact on the infection propagation. Nevertheless, the rooms that require a rigorous control of temperature, humidity and pressure have artificial conditioning. In rooms which are more flexible to these factors, such as wards and rehabilitation areas, natural ventilation is used.

The analysis of the natural ventilation systems, in buildings and in the urban environment, can be conducted by different methods such as: (1) water table; (2) analytical and semi-empirical formulas; (3) in situ measurements; (4) CFD (computational fluid dynamics) simulations; (5) wind tunnel tests [22].

Among these methods, wind tunnel was chosen because it is an important tool during the design conception. Furthermore, it is possible to realize a qualitative and quantitative analysis of the natural ventilation. In this context, the aim of this paper is to evaluate the influence of captor and extractor sheds on the natural ventilation of internal spaces through measurements of air velocity in wind tunnel tests.

\section{Research Method}

\subsection{Wind Tunnel}

Physical models were constructed and tested in a boundary layer wind tunnel at the Environmental Comfort and Applied Physics Laboratory of the School of Civil Engineering, Architecture and Urban Planning, University of Campinas. The dimensions of the test section of the wind tunnel are: width $=0.9 \mathrm{~m}$, height $=0.8 \mathrm{~m}$ (cross-section area $=0.72 \mathrm{~m}^{2}$ ) and length $=4.5 \mathrm{~m}$. The maximum air velocity in the test section is $20 \mathrm{~m} / \mathrm{s}$. The physical model should obstruct not more than $7 \%$ of the cross-sectional area, i.e., the maximum frontal area of the model perpendicular to the wind should be smaller than $0.05 \mathrm{~m}^{2}$. 


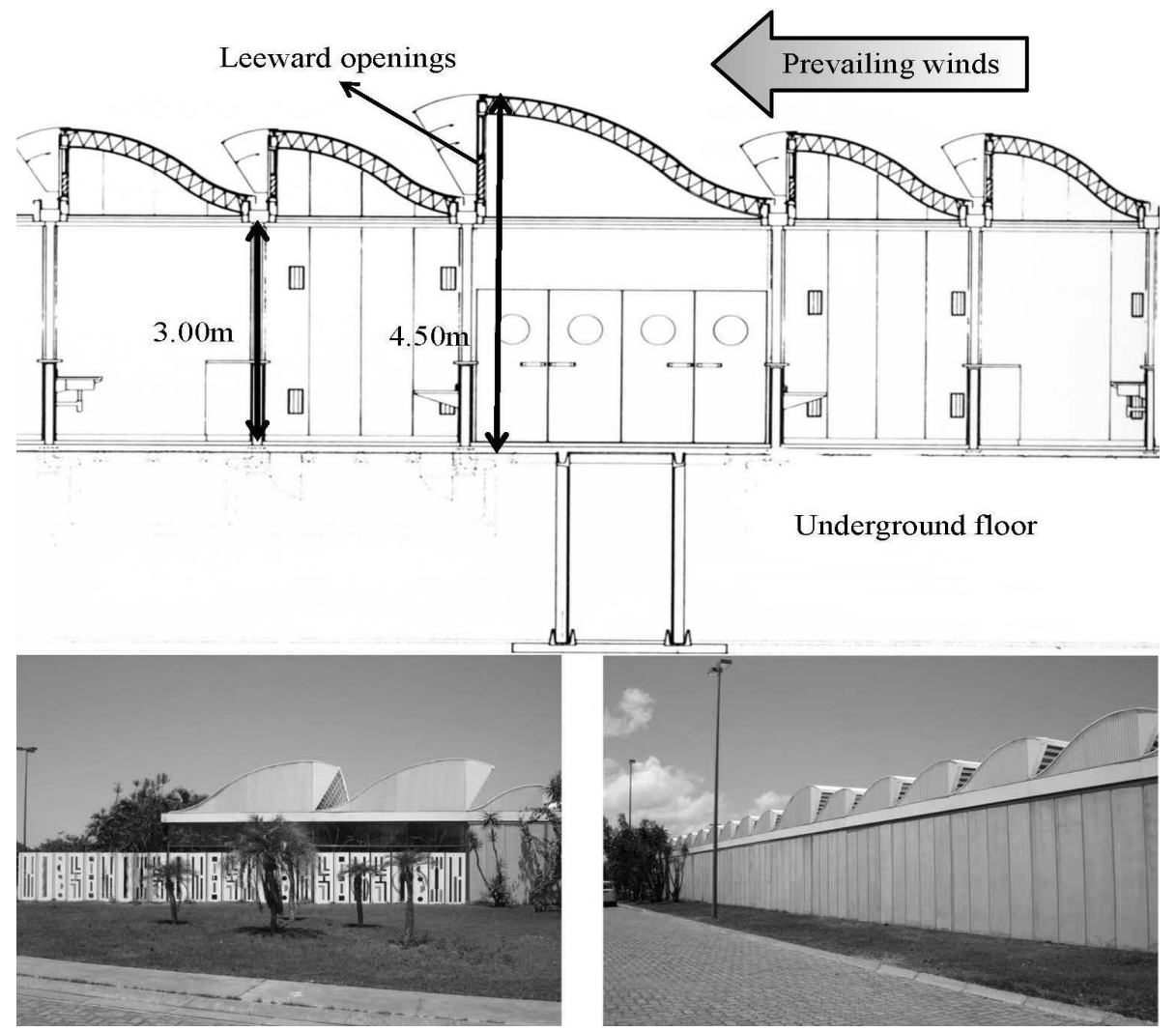

Fig. 2 Sheds of Salvador hospital ${ }^{1}$.

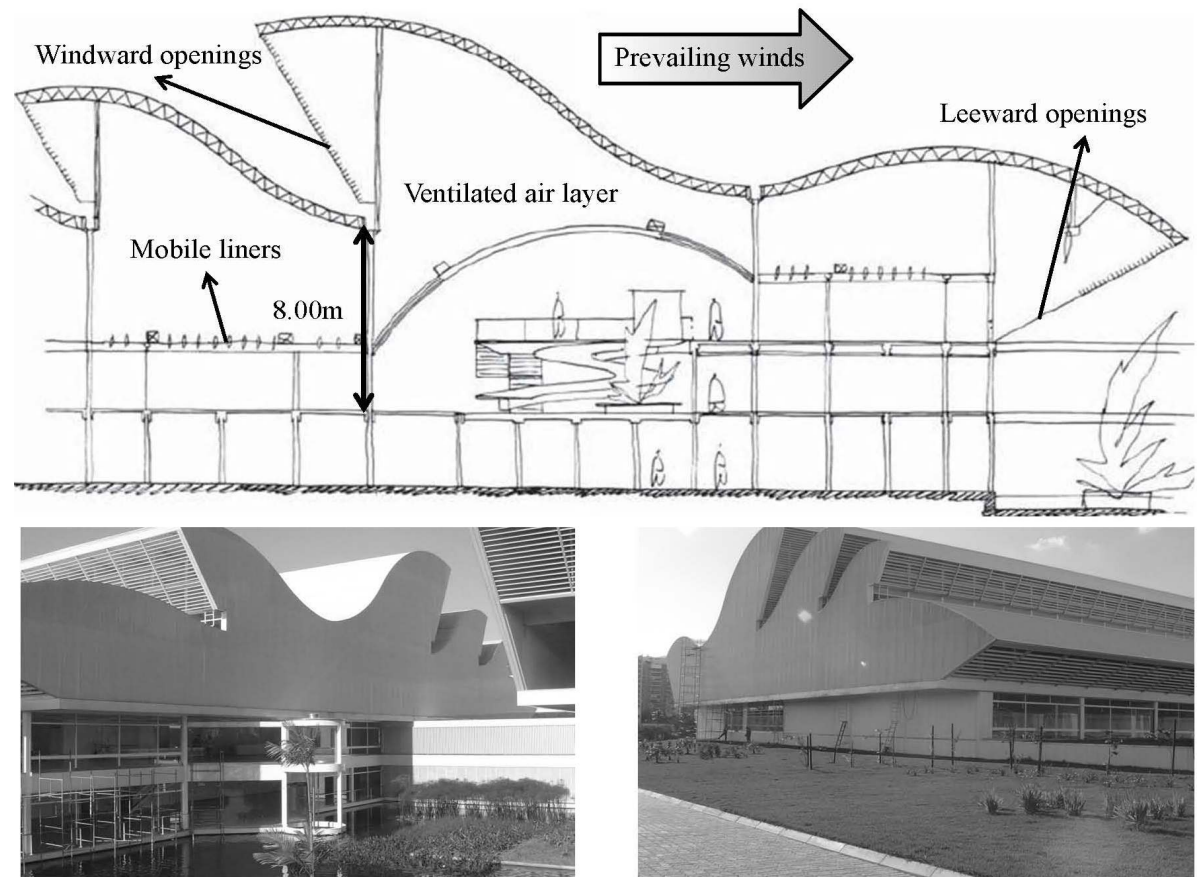

Fig. 3 Sheds of Rio de Janeiro hospital' .

${ }^{1}$ Collection of research on CTRS (Technology Center of the Sarah Network of Rehabilitation Hospitals) by Marieli Lukiantchuki, 2008.

${ }^{2}$ Ibid 1 . 
Table 1 Difference (\%) between the average ratios for Salvador and Rio de Janeiro hospitals.

\begin{tabular}{lllll}
\hline & & Salvador & Rio de Janeiro & Difference (\%) \\
\hline & V2/V1 & 1.20 & 1.15 & -3.9 \\
Average velocity ratios at & V3/V1 & 0.71 & 0.78 & 9.7 \\
each point evaluated & V4/V1 & 0.51 & 0.81 & 61.0 \\
& V5/V1 & 0.67 & 0.86 & 28.3 \\
\hline Average velocity ratios & V6/V1 & 1.25 & 1.19 & -5.2 \\
\hline
\end{tabular}

The boundary layer inside the tunnel was simulated with the installation of turbulence generator obstacles on the floor at the test section entrance, which represent the roughness of the soil. These obstacles produce a velocity profile similar to achieve the minimum requirement of the neutral atmospheric boundary layer for suburban environments [23]. Wind tunnel used for this experiment is shown in Fig. 4.

\subsection{Definition of the Study Object}

The rooms analysed were the wards because they are the places where the patients stay. In the Salvador hospital, the sheds have same geometry throughout the building. Thus, a reduced model was built considering only the ward. In the Rio de Janeiro hospital, the sheds have different geometries and sizes and their openings are positioned leeward and windward. In this case, a reduced model was built, considering the whole building, comprising the ward, gymnasium and individual apartments. However, only the ward was evaluated.

The reduced models of Salvador and Rio de Janeiro hospitals were built on 1:40 and 1:55 scales, respectively, based on the dimensions required by the tunnel test section. The physical models were built with all the details of the natural ventilation system. The material used was $2 \mathrm{~mm}$ transparent acrylic to facilitate the visualization during the tests. The models were designed using AutoCAD 2009 software and cut using laser cutting technology (Universal Laser System). The pieces were assembled using acrylic glue and silicone to seal off possible crevices. Figs. 5 and 6 show the physical models of the two hospitals inside the wind tunnel.

\subsection{Air Velocity Measurements}

The inside and outside wind velocities in the physical models were measured using six Multichannel 54N81 hot-wire anemometers sensors (Dantec) [24]. The range of the calibration reference sensor velocity is $0.2 \mathrm{~m} / \mathrm{s}$ to $30 \mathrm{~m} / \mathrm{s}$ and the measurement error ranges are $1 \%$.

The tests were performed with $60,124,207,290$, 373, 456, 539, 622 and $705 \mathrm{rpm}$ frequencies. For these values, the wind velocity varies from $0.7 \mathrm{~m} / \mathrm{s}$ to $7 \mathrm{~m} / \mathrm{s}$.

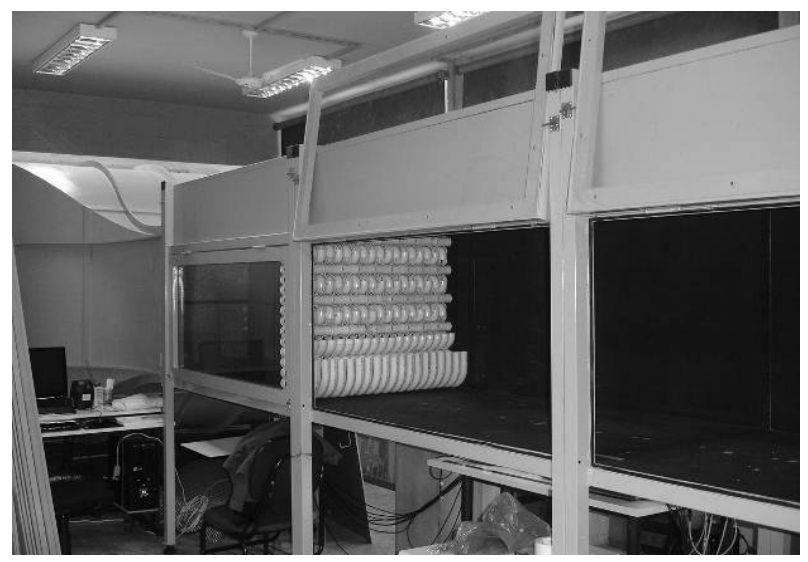

Fig. 4 Wind tunnel used for experiment.

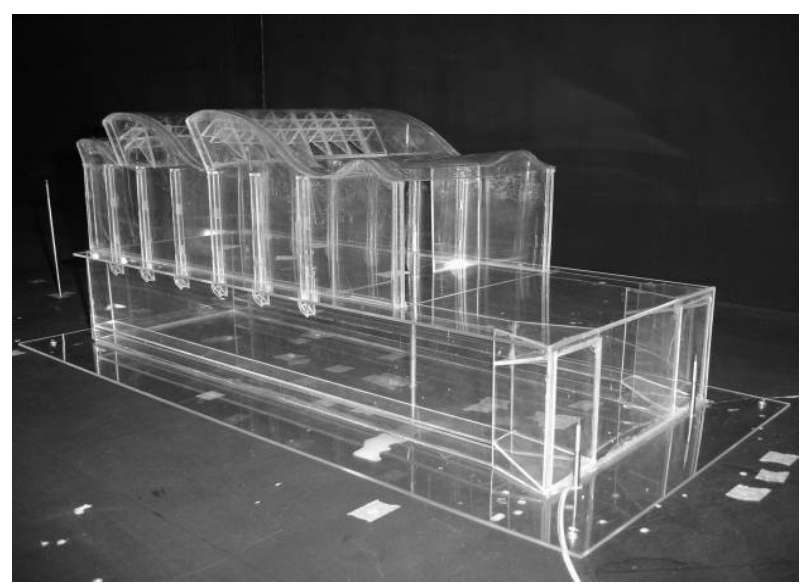

Fig. 5 Reduced model of Salvador hospital. 


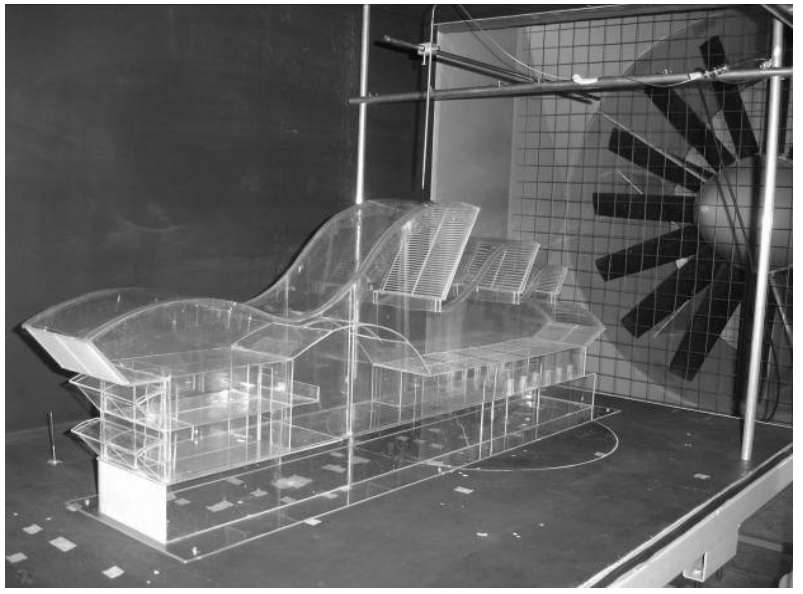

Fig. 6 Reduced model of Rio de Janeiro hospital.

The monthly average values of the wind velocity in Salvador range from $1.92 \mathrm{~m} / \mathrm{s}$ in March to $2.64 \mathrm{~m} / \mathrm{s}$ in July. In Rio de Janeiro, these monthly average values vary from $1.90 \mathrm{~m} / \mathrm{s}$ in June to $2.91 \mathrm{~m} / \mathrm{s}$ in November. Thus, the frequencies tested refer to values according to the local reality. This relationship was highlighted in the research conducted by Labaki et al. [25]. The directions of the prevailing winds are northeast and east, respectively. Each model was tested with the sheds of the buildings as air captors and extractors in order to evaluate the performance of the sheds in both positions.

Four miniature hot-wire anemometer sensors were installed inside the models through holes at their bottom. Three sensors were placed at central points, in the longitudinal direction in relation to the wind incident on the building (P2, P3 and P4). Another sensor was positioned near the air vents on the walls (P5). All internal sensors were placed $0.80 \mathrm{~m}$ from the floor, which is the height of a patient's body lying on a stretcher. Two sensors were installed outside the model. To measure the external wind velocity before reaching the physical model, a sensor was placed in front of the model at a distance equal to $8 \mathrm{~m}$ from the facade of the hospital and $6 \mathrm{~m}$ from the floor (P1). Thus, the value of the undisturbed flow was achieved. Finally, to obtain the wind velocity value near the sheds, a sensor was installed at the top of the external model, $1 \mathrm{~m}$ above the sheds (P6) (Figs. 7 and 8). The tests were performed with the windows open.

\section{Results and Discussion}

This stage of the research was divided into two parts. First, the air velocities in the hospitals in Salvador and Rio de Janeiro were compared in order to evaluate which hospital showed the highest indoor air velocity. In the second part, the performance of the air captors and extractors sheds of the Salvador and Rio de Janeiro hospitals was analyzed and compared. The internal average air velocities for each building in both situations were calculated using a frequency of $290 \mathrm{rpm}$, which is the local average wind velocity in
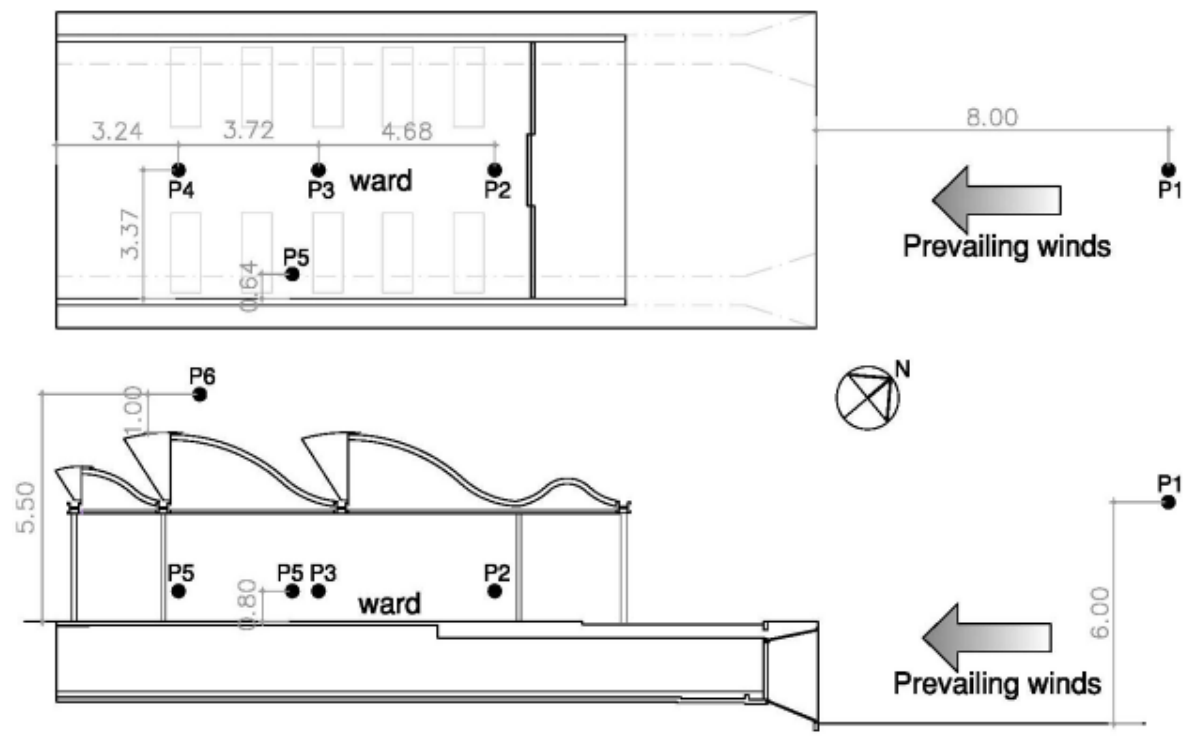

Fig. 7 Location of measuring points in the Salvador hospital (values in $\mathbf{m}$ ). 


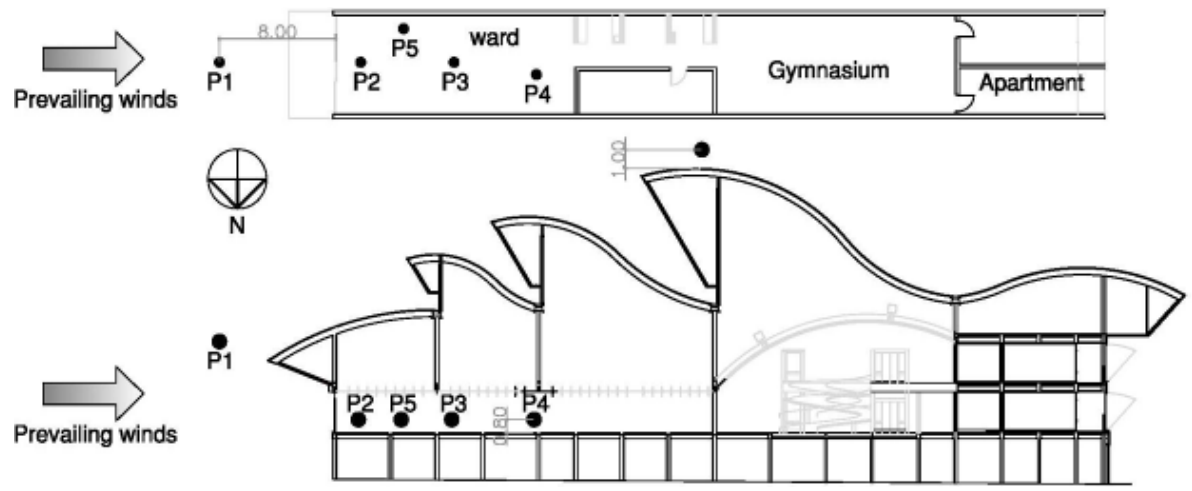

Fig. 8 Location of measuring points in the Rio de Janeiro hospital (values in m).

the warmer months in the cities. In these periods of the year, natural ventilation is extremely necessary to obtain thermal comfort.

\subsection{Air Velocity Measurements}

Figs. 9 and 10 show the air velocity inside and outside the hospitals in Salvador and Rio de Janeiro, with respect to the velocity measured at P1.

The same linear trend is observed in the variation of velocities measured at six points in both hospitals. The air velocities at points P2 (internal) and P6 (above the shed) are higher than that at P1, showing that the air is accelerated due to the narrowing at the front openings near the P2 and the deviation of the flow upwards because of the presence of the sheds (P6).

The velocities at internal points $\mathrm{P} 3$ and $\mathrm{P} 4$ are lower than that at point P1. Although they are in the same longitudinal direction of point $\mathrm{P} 2$, the velocities at points $\mathrm{P} 3$ and $\mathrm{P} 4$ are lower than that at $\mathrm{P} 2$. This reduction occurs because points $\mathrm{P} 3$ and $\mathrm{P} 4$ are in a position where the cross-sectional area to the flow expands. Furthermore, the velocities of the air that comes from the vents located on the ward wall (P5) are lower than that at point P1.

The graphs in Figs. 9 and 10 show that the velocities at points P2 and P6 are similar for the two hospitals, whereas at points $\mathrm{P} 3, \mathrm{P} 4$ and $\mathrm{P} 5$, the velocities in the Rio de Janeiro hospital are higher.

For a better comparison of the velocities at each internal point and the external reference point, the ratio values are presented for each hospital. Figs. 11 and 12 show the velocity ratios at points $\mathrm{P} 2, \mathrm{P} 3, \mathrm{P} 4$, $\mathrm{P} 5$ and P6 to the external velocity (V1) with respect to the air velocity measured at $\mathrm{P} 1$, for each frequency tested, in the case of the hospitals in Salvador and Rio de Janeiro, respectively.

In general, the frontal wind velocity (P1) increase causes a small decrease in the ratio values due to the building interference with the flow, which increases the turbulence and causes energy loss. The increase in velocity at the facade is not fully transformed into a gain of velocity inside and outside the building.

The comparison of the air velocities in the two hospitals shows that the V2 and V6 velocity ratios at points P2 and P6, respectively, present small differences. However, when analysing the values corresponding to points $\mathrm{P} 3, \mathrm{P} 4$ and $\mathrm{P} 5$, the ratios for Rio de Janeiro hospital are significantly higher.

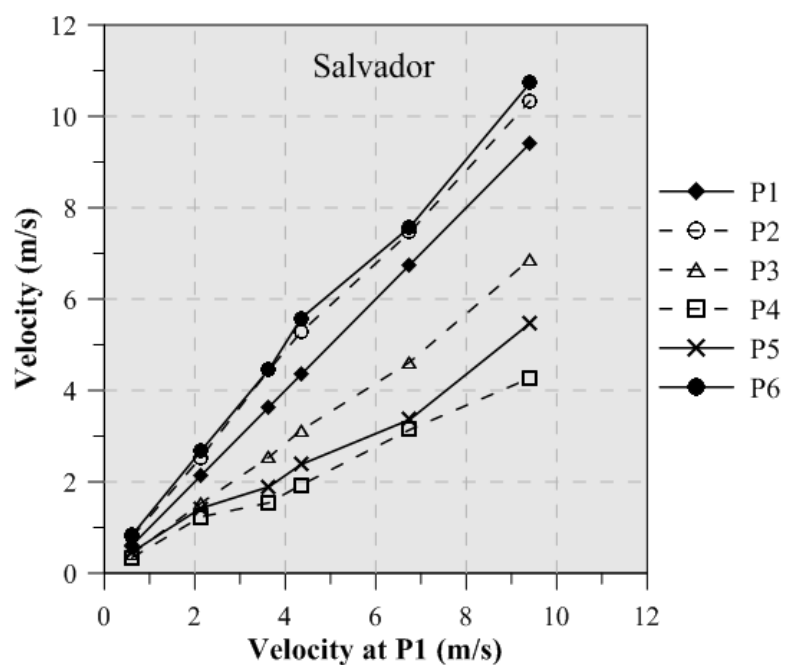

Fig. 9 Internal and external wind velocity with respect to the external velocity (P1) for Salvador hospital. 


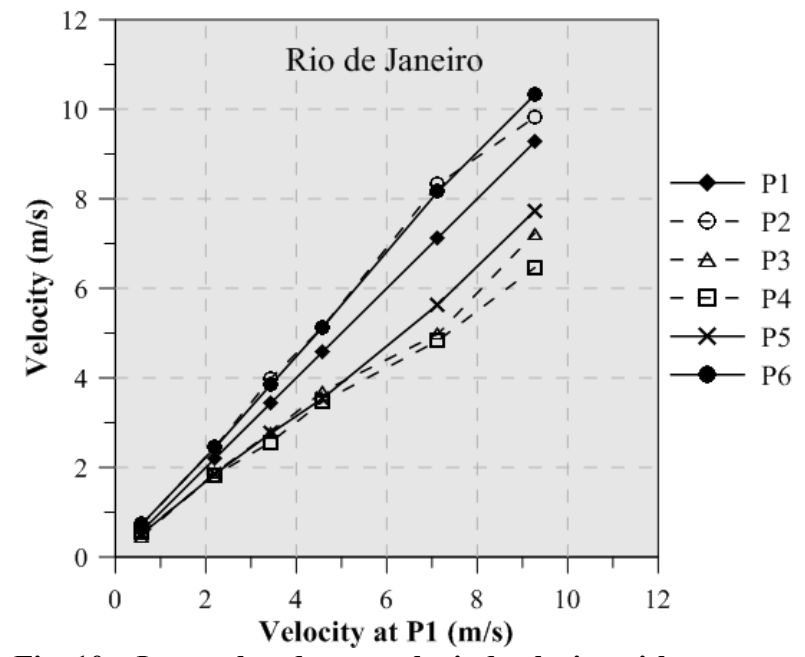

Fig. 10 Internal and external wind velocity with respect to the external velocity (P1) for Rio de Janeiro hospital.

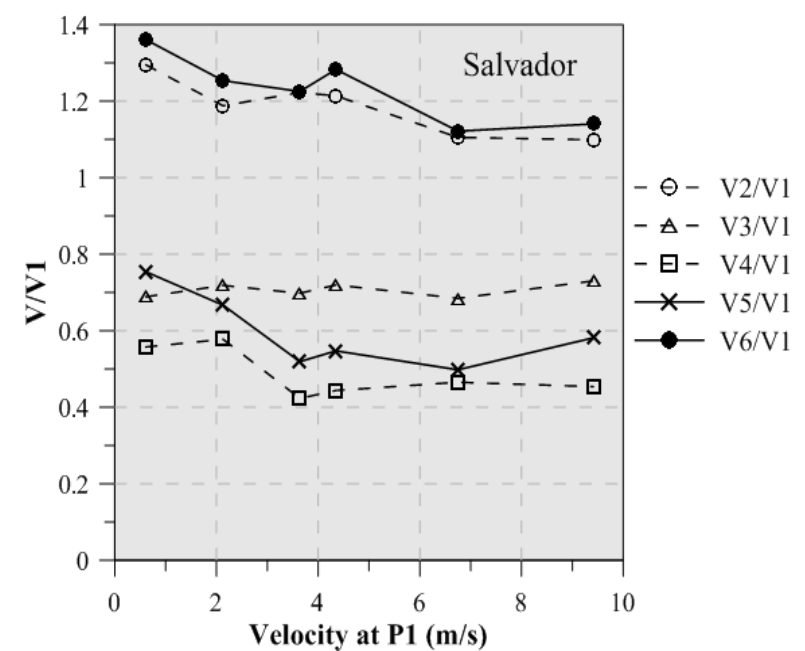

Fig. 11 Ratio of the air velocities at internal and external points to the external velocity for Salvador hospital.

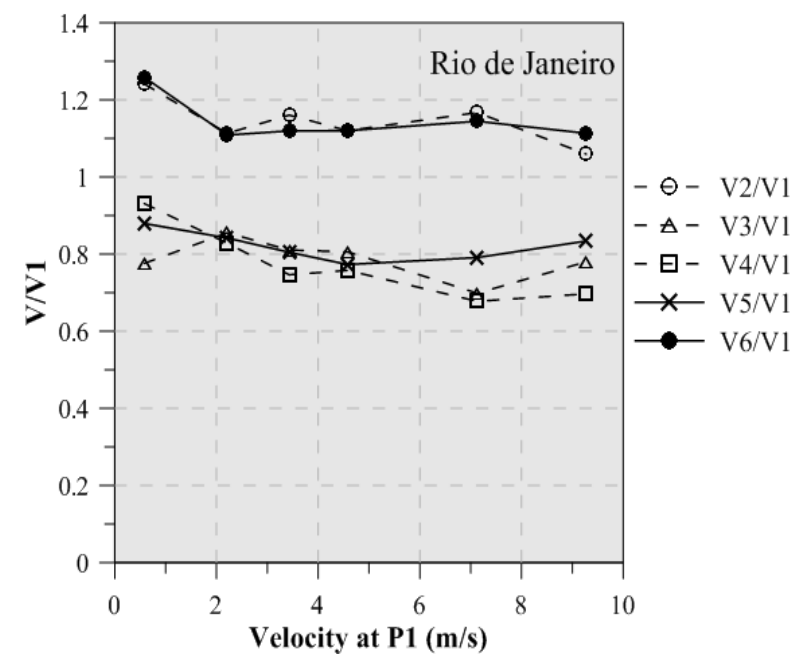

Fig. 12 Ratio of the air velocities at internal and external points to the external velocity for Rio de Janeiro hospital.
The differences $(\%)$ between the average ratios for the two hospitals (Table 1) show that the velocities at the internal points are significantly higher in the hospital in Rio de Janeiro except for the values at points P2 and P6.

In the wards of the hospital in Rio de Janeiro, the indoor air velocity is $17 \%$ higher. The set of shed openings capturing the wind and making it flow through the top of the internal rooms are very efficient in the process of natural ventilation. The variation of the shed heights and their openings, which are larger in the Rio de Janeiro hospital, provides a more intense air flow allowing higher velocities indoors.

\subsection{Air Collectors and Extractors Sheds}

Fig. 13 shows the velocities measured at each point with respect to the tested frequencies for the Salvador hospital, in which sheds work as extractors and collectors of air, respectively.

The average internal air velocity is $1.68 \mathrm{~m} / \mathrm{s}$ with the sheds working as extractors. However, when the sheds work as captors, this average air velocity decreases to $0.95 \mathrm{~m} / \mathrm{s}$, showing a reduction of approximately $43 \%$. Therefore, when the sheds work as extractors of air, the ventilation is more efficient. The geometry of the sheds of the Salvador hospital, which has the same dimensions throughout the building, does not allow good air collection.

The velocity at P6 remains practically the same for both positions with a reduction of approximately $10 \%$ for the sheds that work as captors. This reduction is due to the shed geometry as extractor deviates the air flow upward, increasing its velocity.

Point 2 showed the most significant decrease of all. For the sheds working as extractors, this point achieved the highest velocity values, even higher than the velocities at P1. For the sheds working as captors, the air velocity had a significant reduction of approximately $57 \%$. This decrease occurred because, in the first case, P2 was located near the front opening, where there was a wind bottleneck with a consequent 


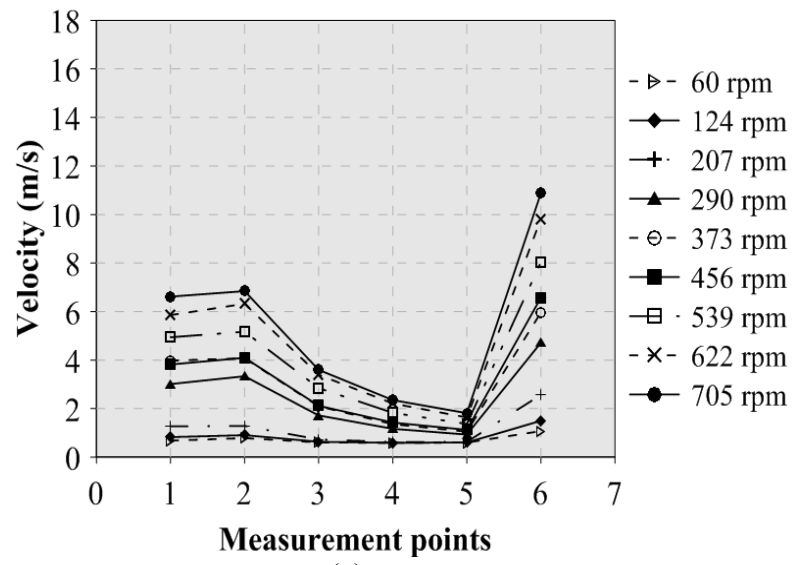

(a)

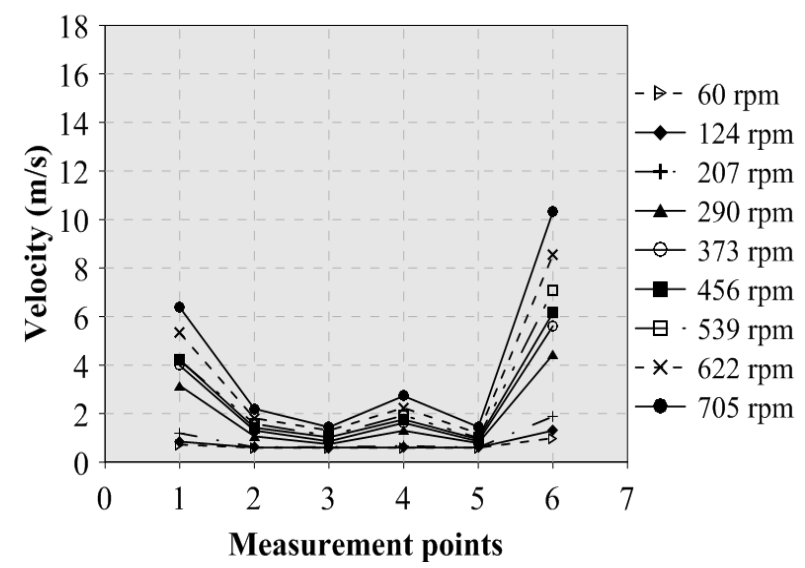

(b)

Fig. 13 Velocities measured at each point with respect to the tested frequencies of the Salvador hospital: (a) air extractor; (b) captor sheds.

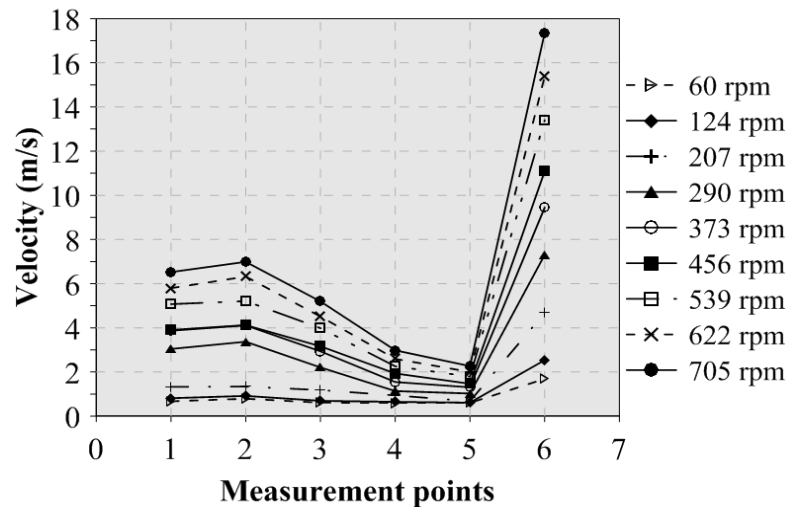

(a)

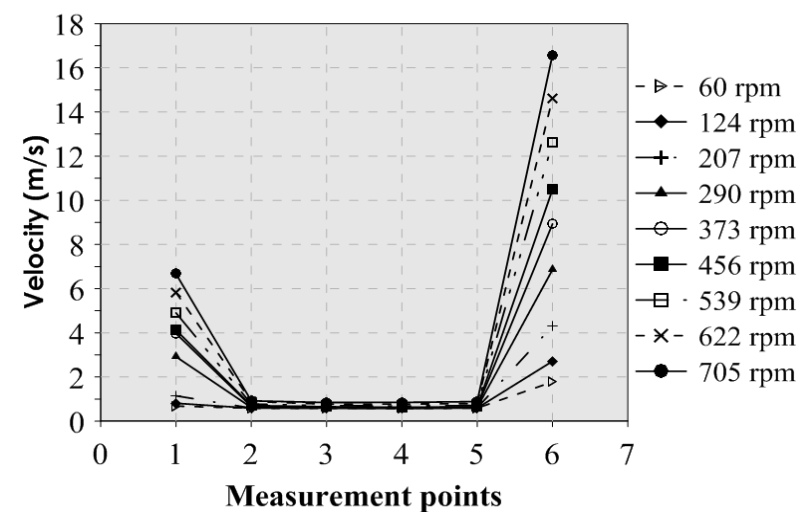

(b)

Fig. 14 Velocities measured at each point with respect to the tested frequencies of the Rio de Janeiro hospital: (a) air captor; (b) extractor sheds.

increase in the air velocity. In the case of the sheds working as captors, the wind did not reach the front opening directly, which caused a reduction in the air velocity at this point.

In the case of $\mathrm{P} 3$, for the air collectors sheds, there was also a significant reduction of approximately $38 \%$, unlike $\mathrm{P} 4$, where the air velocity had a small increase by approximately $8 \%$. This increase was due to $\mathrm{P} 4$ being close to the direct incident winds on the front sheds, which did not occur at Points 2, 3 and 5 due to the shadow that these devices caused on the back shed.

Finally, at P5, there was an air velocity reduction of approximately $10 \%$, which was already expected because when the sheds worked as air collectors, the wind did not enter the underground galleries and, consequently, the air flow through the vents located on the wall decreased.

Fig. 14 shows the velocities measured at each point with respect to the frequencies tested for the Rio de Janeiro hospital, in which sheds worked as collectors and extractors of air, respectively.

The average internal air velocity in the hospital was $2.01 \mathrm{~m} / \mathrm{s}$ when the sheds worked as air captors. This average air flow velocity had a significant reduction of $70 \%(0.60 \mathrm{~m} / \mathrm{s})$ when the sheds worked as air extractors, showing that the actual position of the hospital was more efficient.

For all internal points (P2, P3, P4 and P5), the air velocity showed a significant reduction when the sheds worked as air extractors. On the other hand, the air velocity at P6 showed the same performance in 
both situations.

At P2, the air velocity showed the highest reduction, i.e., approximately $76 \%$. This occurred because of the same reason of $\mathrm{P} 2$ in the Salvador hospital. When the sheds worked as collectors, the air was accelerated due to a narrowing of the front openings, which did not occur in the other case (extractor sheds), because the wind did not enter the front opening directly.

At P3 and P4, there were significant reductions of $67 \%$ and $47 \%$, respectively. However, differently from what was expected, the point located near the vents on the wall (P5), also presented a reduction of approximately $34 \%$. This hospital with the sheds working as extractors of air allowed the air penetration directly from the technical floor. On the other hand, this building, with the sheds working as collectors (the air in the technical floor and around it), was static and showed a high pressure. The wind that reaches the roof generates a pressure reduction, causing an air movement from the location of higher pressure to the location of lower pressure. Thus, the wind causes an upward flow, which is extracted by the cover.

This significant reduction in the internal air velocity in the Rio de Janeiro hospital for the sheds as extractors occurred mainly because when the sheds worked as collectors of air, the set of sheds with large non-uniform openings in large quantities and the larger spacing between these devices provided good air collection and better ventilation indoors.

\section{Conclusions}

Sheds are architectural elements with strong presence in Lima's building projects. Moreover, the study of Salvador and Rio de Janeiro hospitals has shown his concern about the improvement of these elements. Tests in the wind tunnel showed that the ward in the Rio de Janeiro hospital reaches an internal air velocity $17 \%$ higher than that in the Salvador hospital. However, this occurs not only by the use of captor sheds, but also by other factors, such as a set of openings present in larger quantities and dimensions. This statement was confirmed by the satisfactory performance of the sheds in Salvador and Rio de Janeiro hospitals as air extractors and captors, respectively. The geometry of the sheds of the Salvador hospital, which has the same dimensions throughout the building, does not allow good air collection. In the Rio de Janeiro hospital, the non-uniform openings, dimensions of the sheds and the larger spacing between these devices facilitate the wind entry.

According to the tests, both air extractor and captor sheds may show good performance regarding natural ventilation. However, the designer must know how to use them in each case and take full advantage of them. A careful analysis of their geometry, distance between the devices, size of the openings, vertical distance between the inlet and outlet openings and height of the headroom, among other factors, is important to determine when to use them as air captors or extractors.

\section{Acknowledgments}

The authors would like to acknowledge FAPESP (State of São Paulo Research Foundation) for the financial support provided to this research.

\section{References}

[1] C. Alloca, Q. Chen, L.R. Glicksman, Design analysis of single-sided natural ventilation, Energy and Buildings 35 (2003) 785-795.

[2] C. Cândido, R.J. de Dear, L. Lamberts, L.S. Bittencourt, Air movement acceptability limits and thermal comfort in Brazil's hot humid climate zone, Energy and Building 45 (2010) 222-229

[3] D.Z. Chen, P. Bandopadhayhay, J. Haldorsson, C. Byrjalsen, P. Heiselberg, Y. Li, An experimental investigation of a solar chimney model uniform wall heat flux, Building and Environment 38 (2003) 893-906.

[4] C. Afonso, A. Oliveira, Solar chimneys: Simulation and experiment, Energy and Buildings 32 (2000) 71-79.

[5] W. Ding, Y. Hasemi, T. Yamada, Natural ventilation performance of a double-skin façade with a solar chimney, Energy and Buildings 37 (2005) 411-418.

[6] M. Maerefat, A.P. Haghighi, Passive cooling of buildings 
by using integrated earth to air heat exchanger and solar chimney, Renewable Energy 35 (2010) 2316-2324.

[7] J. Waewsak, K. Hirunlabh, U.C. Shin, Performance evaluation of the BSRC (Building Scientific Research Center) multi purpose bio-climatic roof, Building and Environment 38 (2003) 1297-1302.

[8] L. Neves, M. Roriz, F.M. da Silva, Modeling a solar chimney for maximum solar irradiation and maximum airflow for low latitude locations, in: 12th Conference of International Building Performance Simulation Association, Sydney, 2011.

[9] M.N. Bahadori, M. Mazidi, A.R. Dehghani, Experimental investigation of new designs of wind towers, Renewable Energy 33 (2008) 2273-2281.

[10] H. Montazeri, R. Azizian, Experimental study on natural ventilation performance of one-sided wind catcher, Building and Environment 43 (12) (2008) 2193-2202.

[11] D.G.F. Lôbo, L.S. Bittencourt, A influência dos captadores de vento na ventilação natural de habitações populares localizadas em climas quentes e úmidos (The influence of wind captors in natural ventilation of social housing located in hot and humid climates), Revista Ambiente Construído 3 (2003) 57-67. (in Portuguese)

[12] J. Gandemer, G. Barnaud, J.R. Millet, C. Sacre, Guide sur la climatisation naturelle de l'habitat en climat tropical humide, Tome 1: Methologie de prose em compte des parameters climatiques dans l'habitat et conseils pratiques (Guide of Natural Cooling of the Humid Tropical Climate, Volume 1: Methodology to Climatic Parameters in Housing and Practical Advices), Report for the CSTB (Centre Scientifique et Technique du Bâtiment) 1992. (in French)

[13] T. Stathopoulos, P. Saathoff, Codification of wind pressure coefficients for sawtooth roofs, Journal of Wind Engineering and Industrial Aerodynamics 43 (1-3) (1992) 1727-1738.

[14] P. Saathoff, T. Stathopoulous, Wind loads on building with sawtooth roofs, ASCE (American Science of Civil Engineers) Journal of Structural Engineering 118 (2) (1991) 429-446.

[15] J.D. Holmes, Wind loading of multi-span, in: First
National Structural Engineering Conference, Melbourne, 1983.

[16] P.A. Blackmore, Wind Loads on Pitch Roof Multi-span Buildings, Building Research Establishment, 1986.

[17] M.A. Lukiantchuki, E. Matsumoto, R.M. Caram, J.F. Matos, L.C. Labaki, Study of natural ventilation provided by sheds in hospital buildings through wind tunnel measurements, in: 6th Windsor Conference, London, 2010.

[18] M. Risselada, G.A. Latorraca, Arquitetura de Lelé: Fábrica e Invenção (Lelé's Architecture: Factory and Invention), Imprensa Official, São Paulo, 2011.

[19] M.A. Lukiantchuki, R.M. Caram, The use of sheds to promote the natural ventilation: The work of Brazilian architect João Filgueiras Lima, Lelé, in: 7th Windsor conference 2012, London, 2012.

[20] T.V. Hooff, B. Blocken, L. Aanen, B. Bronsema, A Venturi-shaped roof for wind-induced natural ventilation of buildings: Wind tunnel and CFD (computational fluid dynamic) evaluation of different design configurations, Building and Environment 46 (2011) 1797-1807.

[21] J. Perén, P. Greco, R. Caram, Computational analysis of sheds in Sarah Network Hositals using the software CFX, in: IX National and V Latin American conference of comfort in Built Environment, Brazil, 2008.

[22] Q. Chen, Ventilation performance prediction for buildings: A method overview and recent applications, Building and Environment 44 (2009) 848-858.

[23] E. Matsumoto, L.C. Labaki, R.M. Caram, A aplicação de ensaios em túnel de vento no processo de projeto (The application of wind tunnel tests in the design process), in: $\mathrm{O}$ processo de projeto em Arquitetura: da teoria à tecnologia (The Design Process in Architecture: From Theory to Technology), Oficina de Texto, Campinas, 2011, pp. 365-373.

[24] E. Ower, R.C. Pankhurst, The Measurement of Air Flow, 5th ed., Pergamon Press, Oxford, 1977.

[25] L.C. Labaki, E. Matsumoto, J.M.S.C. Morais, T.A. Medinilha, M.C.S. Oliveira, Ventilation in self-built houses - A study through wind tunnel measurements in Campinas, Brazil, International Journal of Ventilation 10 (2011) 115-123. 